\title{
Morphological awareness in L2 Spanish: What is learned incidentally and what requires explicit teaching?
}

\author{
CLAUDIA H. SÁNCHEZ GUTIÉRREZ \\ University of California, Davis \\ chsanchez@ucdavis.edu
}

\begin{abstract}
The development of morphological awareness positively impacts vocabulary learning, inferencing skills or reading comprehension. However, it is currently given very little attention in Spanish as a Second Language textbooks, due to the prevailing belief that derivational morphological knowledge can be developed without any explicit teaching. This idea has been repeatedly contested in the literature, and the present study aims to add to this ongoing discussion by specifying the aspects of morphological knowledge that would benefit the most from explicit pedagogical treatment. Four tasks were designed, which tapped into relational and distributional knowledge, both at the receptive and productive level. Students enrolled in three successive SSL course levels completed the tasks, as did one group of beginners who completed them twice: before and after a four-session long morphological training. Results indicate that participating in that training was advantageous in most tasks, but particularly so for the one that required distributional productive skills. Pedagogical implications of these results are further discussed.
\end{abstract}

\section{Keywords}

Derivational morphology; morphological awareness; explicit teaching; morphemes. 


\section{Conciencia morfológica en ELE: ¿Qué se aprende incidentalmente y qué requiere enseñanza explícita?}

\section{Resumen}

El desarrollo de la conciencia morfológica presenta un impacto positivo en el aprendizaje de vocabulario, las habilidades de inferencia léxica o la comprensión lectora. Sin embargo, en este momento apenas se incluyen materiales relacionados con esta materia en los manuales de Español Lengua extranjera, debido a la creencia de que el conocimiento morfológico se desarrolla sin necesidad de instrucción explícita. Esta idea ha sido desechada en la bibliografía repetidas veces y este estudio pretende aportar más a esta discusión al determinar qué aspectos específicos de la conciencia morfológica obtienen mayores beneficios de un tratamiento pedagógico explícito. Se diseñaron cuatro tareas, enfocadas cada una bien en el conocimiento relacional o el combinatorio, tanto a nivel receptivo como productivo. Varios grupos de estudiantes inscritos en cursos de español de tres niveles sucesivos completaron las tareas. También lo hizo un grupo de aprendices que participó en un entrenamiento morfológico que duró cuatro sesiones. Los resultados demuestran que dicho entrenamiento fue beneficioso para la compleción correcta de todas las tareas pero más aún en el caso de la tarea enfocada en conocimientos combinatorios productivos. Al final del artículo se discuten las implicaciones pedagógicas de estos resultados.

\section{Palabras clave}

Morfología derivativa; conciencia morfológica; enseñanza explícita; morfemas. 


\section{Introduction}

While vocabulary learning is usually considered as a simple association of form and meaning, studies have repeatedly demonstrated that deeper knowledge about a word results in longer term memorization (Schmitt, 2014). Concretely, Nation (2001) proposes that there are nine aspects that constitute deep lexical knowledge, ranging from knowing how a word is pronounced to how frequently it is used or in what contexts it should be used or avoided. One of these aspects is the knowledge of word parts. Indeed, Nation posits that an adequate knowledge of a word's form requires the recognition of the morphemes it is composed of, as well as the realization that words are part of larger families, bound by shared affixes and/or roots. This ability to recognize and manipulate morphemes was coined as morphological awareness by Carlisle (1995) and has been proven to positively influence vocabulary development and lexical inferencing (Bowers \& Kirby, 2010; Hu \& Nassaji, 2014; Morin, 2003, 2006; Nassaji, 2003, 2006).

Nonetheless, Sánchez Gutiérrez (2014) and Robles García and Sánchez Gutiérrez (2017) found that Spanish as a Second Language (SSL) textbooks include very few references and exercises focused on the development of morphological awareness. Additionally, not only is the number of exercises extremely scarce, but those exercises tend to include incorrect information where morphemes are confused with graphical word endings with no identifiable meaning. This pattern was observed in textbooks published in the US but also others from European publishers, indicating that the insufficient treatment of morphological skills is persistent in both publishing areas. In a similar vein, Marcos Miguel (2017) recorded five SSL instructors in their classes for two weeks and observed a very limited number of teaching episodes where they referred to morphological information and, when it happened, it was mostly unplanned and improvised. These results are in line with findings by de Miguel García (2005), who sent a questionnaire to SSL instructors about their vocabulary teaching practices and found very little evidence of them using morphological information as part of lexical learning. Results from these textbook and classroom analyses offer a disturbing picture of insufficient attention to word parts and may be driven by the false belief that derivational morphology is an aspect of word knowledge that can be learned incidentally, without any explicit treatment in the classroom. This belief is materialized in the Plan Curricular del Instituto Cervantes (Instituto Cervantes, 2006), which lists the contents that should be taught at different proficiency levels of SSL, and includes word parts as an inferencing strategy but not as a content that needs to be taught, taking for granted that learners possess morphological knowledge already, and can thus use it to recognize familiar morphemes in newly encountered words.

As appealing as it would be to think that learners can simply recognize roots and affixes, identify morphological families, and use such morphemes in creative ways without any teaching involved, this thought has been repeatedly challenged in the literature. Indeed, several claims have been made about the incomplete development of morphological awareness in learners of SSL, proving that incidental learning is not sufficient in this area. For instance, Marcos Miguel (2012) shows how SSL learners with 
English as their first language (L1) do develop morpheme recognition skills but have a harder time, even at advanced levels of proficiency, when it comes to using those morphemes to create new words. According to the author, most issues come from an incomplete knowledge of morphemes' distributional rules, an interpretation that is shared by Morin (2003). Affixes have restricted uses, such that -miento [-ment] or -ble can only be applied to verbs in order to create nouns and adjectives respectively, while -mente [-ly] is applied to adjectives to form adverbs. What was observed in the previously cited studies is that even advanced learners keep incorrectly using -miento with nouns or -mente with verbs. These types of errors have been found both in experimental, more controlled, settings, such as the studies referenced earlier, and in corpus studies (Marcos Miguel \& Sánchez Gutiérrez, 2020; Whitley, 2004), indicating that they are due to incomplete learning rather than a difficulty of the testing task itself.

In sum, while it is true that learners do develop some aspects of morphological awareness when their L1 is typologically close to their L2, others present serious challenges for them. In child language development, Tyler and Nagy (1989) proposed that there are three aspects of morphological awareness that arise sequentially. First, children learn to identify the presence of units that are smaller than words but carry meaning, namely morphemes. This initial phase encompasses the development of what is known as relational knowledge. Subsequently, they realize that specific suffixes pertain to different word classes, such that words ending in -miento are nouns and those ending in -ble are adjectives. This is known as syntactic knowledge. Finally, they discover that -miento and -ble can only be applied to verbs and never to nouns or adjectives, when forming new words. This type of knowledge is known as distributional knowledge and is the last to be developed. It is also the knowledge type that seems to present most difficulties for learners of SSL, who seem to struggle with it even when most linguistic aspects of their L2 are mastered and used fluently (Marcos Miguel \& Sánchez Gutiérrez, 2020; Whitley, 2004).

Additionally, while relational and syntactic knowledge can eventually be mastered without an explicit pedagogical treatment, Sánchez-Gutiérrez and Hernández Muñoz (2018) demonstrated that results differ when those aspects are tested at the productive or receptive level. Indeed, the authors asked students enrolled in three consecutive SSL courses in college to complete four tasks that all focused on morphological relational knowledge but differed in terms of modality (productive vs. receptive) and task difficulty. Results indicated that, whereas receptive tasks were mastered at the end of the first year of SSL courses, productive ones either took longer to improve, or even did not improve at all when the task was more creative and less guided. This indicates that both the type (i.e., relational, syntactic, distributional) and the modality (i.e, receptive vs. productive) of morphological tasks could influence the learning patterns of SSL learners.

In this context, it is now necessary to assess whether explicit teaching could play a role in developing the aspects of morphological awareness which seem to be more challenging for SSL learners. The few studies so far that have looked into the effects of explicit teaching on morphological awareness development and vocabulary learning present encouraging results, indicating that morphological awareness raising could 
overcome some of the difficulties observed when learners are left alone in learning morphology incidentally (Friedline, 2011; Morin, 2003, 2006). However, no study, to the best of our knowledge, has directly compared the effects of explicit teaching on different aspects of morphological knowledge. The present study aims to address this gap in the literature by assessing the benefits of explicit teaching over incidental learning on the development of two aspects of morphological awareness: relational and distributional knowledge, both in production and in detection. Concretely, the study includes two sub-studies. In Study 1, the tasks are completed by students enrolled in three successive language courses, which allows to assess whether results in each task develop over time as students' overall linguistic proficiency increases. Study 2 follows a pre-test/post-test design, where a group of students receives morphological instruction whereas another one does not. Improvements in the post-test are then compared among both groups. The results of both studies will make it possible to assess in which specific tasks explicit teaching benefitted the students the most, when compared with what they developed on their own by simple exposure to the language in class.

\section{Methods}

\subsection{Participants}

\subsubsection{Study 1: Cross-sectional study}

One hundred sixty-seven SSL learners participated in this study, who were enrolled in SSL courses in a university in the U.S. Ninety-four were females and 73 were males. Their mean age was of 19 , with a minimum of 17 and a maximum of 27 . All of them were native speakers of English. They were enrolled in three different levels of SSL courses: 100 (first year SSL courses), 200 (second year SSL courses) and 300 (literature, linguistics and culture courses for Spanish majors). Students at the 100 level had studied Spanish for 3.4 years on average, whereas students at the 200 and 300 levels had studied Spanish for 5.3 and 7.6 years respectively. The equivalences with the levels established in the Common European Framework of Reference for Languages (Council of Europe, 2001) would be as follow: 100-level = A1, 200-level = A2, and 300-level = B1.

Sixty-two participants were enrolled in 100-level courses, 45 in 200-level courses, and 62 in 300-level courses.

\subsubsection{Study 2: Instructional study}

The 62 students enrolled in 100-level courses participated in this second study. Twenty-eight were in the critical group, which received the explicit morphological awareness training. The remaining 33 were part of the control group, which did not receive any explicit morphological awareness treatment. Both completed the morphological tasks during the fourth week of the semester, as did all students in Study 1 , but then completed the tasks for a second time, during week nine. 


\subsection{Tasks}

\subsubsection{Receptive task}

Twenty words were presented to the participants. Half were morphologically complex words composed of a root and a suffix, whereas the other half were words that were morphologically simple, from a synchronic perspective. Both types of words were matched for frequency and length so that participants would not be tempted to make decisions based on visually obvious differences. Students were asked to (1) surround words that they thought had more than one morpheme, and (2) indicate with a bar where the graphic limit was between the morphemes. The complete list of items is presented in Table 1, where complex words are bold-typed.

Table 1: Detection task

\begin{tabular}{|l|l|l|l|}
\hline 1. lámpara & 6. proceder & 11. masajista & 16. accesible \\
\hline 2. elemento & 7. mochila & 12. votante & 17. cocina \\
\hline 3. heladero & 8. delgadez & 13. mañana & 18. pintar \\
\hline 4. calendario & 9. museo & 14. patinador & 19. belleza \\
\hline 5. asistencia & 10. primero & 15. heroísmo & 20. firmeza \\
\hline
\end{tabular}

The first step they needed to take in completing this task was to identify roots and suffixes that they had seen in other words, which would be considered as relational knowledge. The second step required that they use their distributional knowledge to identify where the limit between both parts would be. Indeed, if they put the bar at the wrong place, they may have identified that there were two morphemes but not know exactly which suffix it is and to what type of words it can be applied to.

\subsubsection{Productive task}

Inspired by word fluency tasks that are used in neuropsychological diagnostic (Thurstone, 1938), a task was designed where participants were asked to write as many words as they could in one minute that included a given suffix. They completed this task with three different suffixes: -al, -ista, and -miento. The first one forms adjectives, the second forms both adjectives and nouns, and the third only nouns. The three suffixes have cognate equivalents in English: -al, as in profession-al or addition-al, -ist, as in psycholog-ist or social-ist, and -ment, as in invest-ment or establish-ment. This decision was made because some of the participants would have a very low proficiency and suffixes that would not be as close to English could have resulted in confusions between real suffixes and purely orthographic word endings.

In addition to writing as many words that they knew with that suffix, participants were also requested to write possible words, namely words that they may never have encountered but that could potentially be formed with that suffix. For example, in English, the word *taxist does not exist, but it is possible, in the sense that it correctly uses the suffix -ist to refer to a profession related to an object denoted in the root (i.e., taxi). So, even though the word itself is not listed in the dictionary, it is understandable and follows correct distributional rules, similar to those used for words that do exist, such as saxophonist or trumpetist. While the number of existing words listed by the 
participants provides an indication of their relational knowledge at a productive level, the number of possible words gives insights into their ability to use distributional knowledge to accurately combine roots and suffixes. Therefore, the task offers relevant information on participants' grasp of both relational and distributional knowledge in the context of a production task.

\subsection{Procedures}

\subsubsection{Study 1: Cross-sectional study}

The test was completed in the usual classroom, with the instructor of the course present at all times, during the fourth week of the semester. The researcher briefly presented the study, asked the students to sign the consent forms and explained that they had 20 minutes to complete the test and the demographic questionnaire. The productive test was done first, as the researcher had to make sure that everybody had one minute, no more, to write the words for each one of the three suffixes. When all three suffixes were responded to, the researcher proceeded to explain the steps for the second task and gave participants 10 minutes to complete it. At the end of the data collection session, class continued as usual and the researcher left.

\subsubsection{Study 2: Instructional study}

\subsubsection{Testing procedure}

The same procedure was followed for the pre-test of Study 2. The pre-test was completed at the exact same time than students enrolled only in Study 1. Participants in Study 2 (both the control and the critical group) completed both tasks again, following the same procedure, at the end of the pedagogical treatment, during week nine of the semester.

\subsubsection{Instructional procedure}

The instructional treatment was organized in four sessions of 25 minutes. The usual instructor of the class was present at all times, but the researcher was in charge of presenting the materials and handling the sessions. During the first session, students were taught how to differentiate morphological relations (e.g., sol [sun] - solar [solar]) from semantic (e.g., sol - luna [moon]) or orthographic ones (e.g., sol - soldado [soldier]). After a series of examples to raise awareness on what constitutes a morphological relation between words that look similar, the researcher introduced the key terms in derivational morphology, such as root or suffix. Students were asked to complete a work sheet in pairs. Those work sheets required them to find information about a specific suffix. They had to answer questions about the meaning(s) of the suffix, its allomorphs, the word classes it can be applied to and what part-of-speech resulted from that combination. During the second session, each group presented the information they had gathered about their suffix, and the researcher completed the data, or corrected them when necessary, as they wrote all the information about the different suffixes on the blackboard. The third session introduced morphological decision trees to create new words in Spanish. These trees present the different decisions that one needs to make in 
order to decide which suffix is necessary to form a given type of word and what specific word formation rules need to be taken into account at each step. An example of decision tree is provided in Figure 1.

Your initial word is a verb.

You want to create a noun

Suffixes available: -ción, -miento

Is your verb ending in:
You want to create an adjective

Suffixes available : -ble

Is your verb ending in:
$A R ?$

$E R ? \quad I R ?$

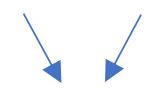

-ación/-amiento

-ición/-imiento

$A R ? \quad E R ? \quad I R ?$

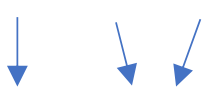

-able -ible

Figure 1. Example of morphological decision tree

Subsequently, in order to also practice those decisions in the other direction, students were asked to decompose words according to the rules the learned. They were given morphologically complex words, such as nacionalización, and had to strip each suffix until the remaining word was the smallest one possible that still had a meaning of its own. These decompositions were then presented in a matrix as the one in Table 2.

Table 2. Example of word matrix

\begin{tabular}{|l|l|}
\hline \multicolumn{2}{|l|}{ NACIONALIZACIÓN } \\
\hline nacionalización & nacionalizar + ción \\
\hline nacionalizar & nacional + izar \\
\hline nacional & nación + al \\
\hline nación & nación \\
\hline
\end{tabular}

The last session was organized as a morphology contest. Students worked in pairs and their challenge was to create the longest possible word in Spanish with the different suffixes and word formation rules that they had discovered during the first three sessions. During the first 15 minutes of the session, the researcher wrote words on the board and students had to create a new word as quickly as possible. First, they were asked to add only one suffix, and to incrementally add some more. Each creation was then written on the board and the researcher and the students decided whether there 
was any rule that had not been respected in forming the invented word. Once this review and practice exercise had been carried out, the actual contest started and participants were asked to work in pairs to write down the longest possible Spanish word, using as many suffixes as possible. At the end of class, each group presented their words and everybody else had to figure out what its meaning was.

This short and intensive pedagogical intervention aimed to develop relational, syntactic and distributional knowledge of specific suffixes and practice them both in recognition and production exercises. Students were expected to be able to recognize those suffixes when they encountered them in new words, and to create new possible (but yet inexistent) words with them. Twenty of the 29 students who were in the critical group completed a voluntary questionnaire about the morphological training. When asked how useful the training was, on a scale from 1 (completely useless) to 7 (extremely useful), the average response was 5.05, which indicates overall satisfaction.

\section{Results}

\subsection{Receptive task}

\subsubsection{Study 1: Cross-sectional study}

Figure 2 presents the percentage of complex words that were detected, correctly segmented into morphemes, or undetected, at each course level. In the next paragraphs, the evolution of correct detections and correct segmentations at the different course levels will be analyzed further.

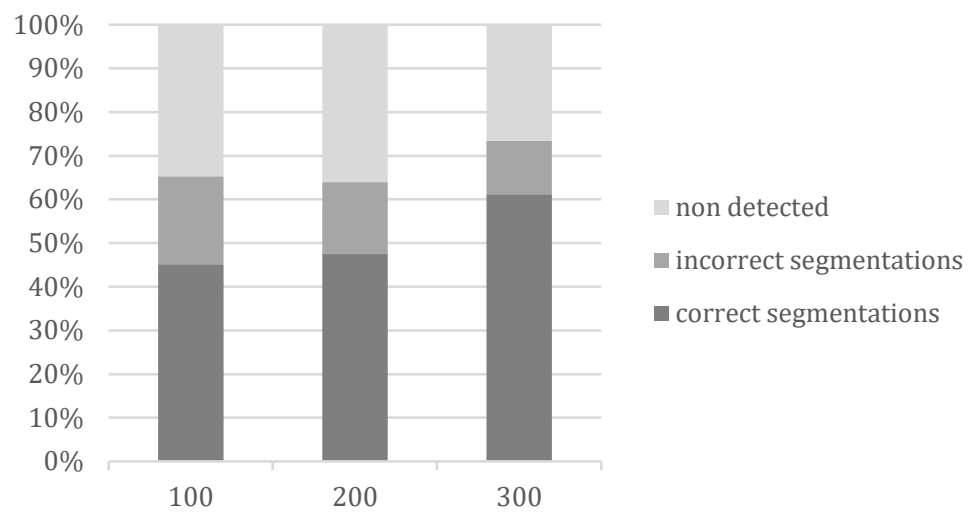

Figure 2. Percentage of correct segmentations, incorrect segmentations and undetected complex words per course level

A one-way anova was carried out on the mean number of correct detections per participant, with a three-level factor of course level (i.e., 100, 200, 300). Results did not show a significant group effect ( $p>05)$, indicating that scores remained similar at all course levels. A second one-way anova was carried out on the average number of correct segmentations per participant, with a three-level factor of course level (i.e., 100, $200,300)$. This time, a significant group effect was observed, $F(2,151)=8,99, p<.01$. Post-hoc pairwise comparisons with a Bonferroni correction show that there were significant differences between participants at the 100-level and the 300-level, with 
additional significant differences between 200-level and 300-level students. The difference between 100 and 200 level students' results did not reach significance.

Table 3. Average number of correct detections and segmentations, with standard deviations, per course

\begin{tabular}{|c|c|c|}
\hline Course level & Correct detections & Correct segmentations \\
\hline 100 & $6.53(1.94)$ & $4.51(1.76)$ \\
\hline 200 & $6.39(2.42)$ & $4.76)$ \\
\hline 300 & $7.34(2.17)$ & $6.12(2.28)$ \\
\hline
\end{tabular}

Overall, these results indicate that correct detections, which require relational knowledge, develop quickly, with around $60 \%$ of correct responses already in level 100 students. However, this initial advantageous situation does not continue improving over time and little change is observed in the next couple of years of language instruction. When it comes to correct segmentations, which are related to distributional knowledge, less than $50 \%$ of the words are correctly segmented at the 100 level, but this result does improve significantly with time. Indeed, by the end of the Spanish major, students are able to segment approximately six out of 10 of the words correctly. Thus, in this receptive task, relational knowledge seems to develop quickly and then stagnate, whereas distributional knowledge does present a more gradual and slow development.

In addition to the quantitative analysis of correct detections and segmentations, the percentage of filler words that were falsely recognized as morphologically complex was also studied. On average, learners at the 100 level wrongly recognized those simple words as complex $21.23 \%$ of the time, this number was reduced to $12.89 \%$ at the 200 level and then rose again to $17.57 \%$ at the 300 level. Overall, the pattern indicates that 100 level learners tended to identify more words as complex, which is a tendency that seemed to appear again at the 300 level, while momentarily being reduced at the 200 level. Interestingly, the pattern is not one of linear reduction in false identifications, but rather a U-shaped process. However, a $t$-test to compare results between 100 and 200 level students did not reach significance, $p=.23$, nor did the $t$-test that compared between 200 and 300 level students, $p=.44$.

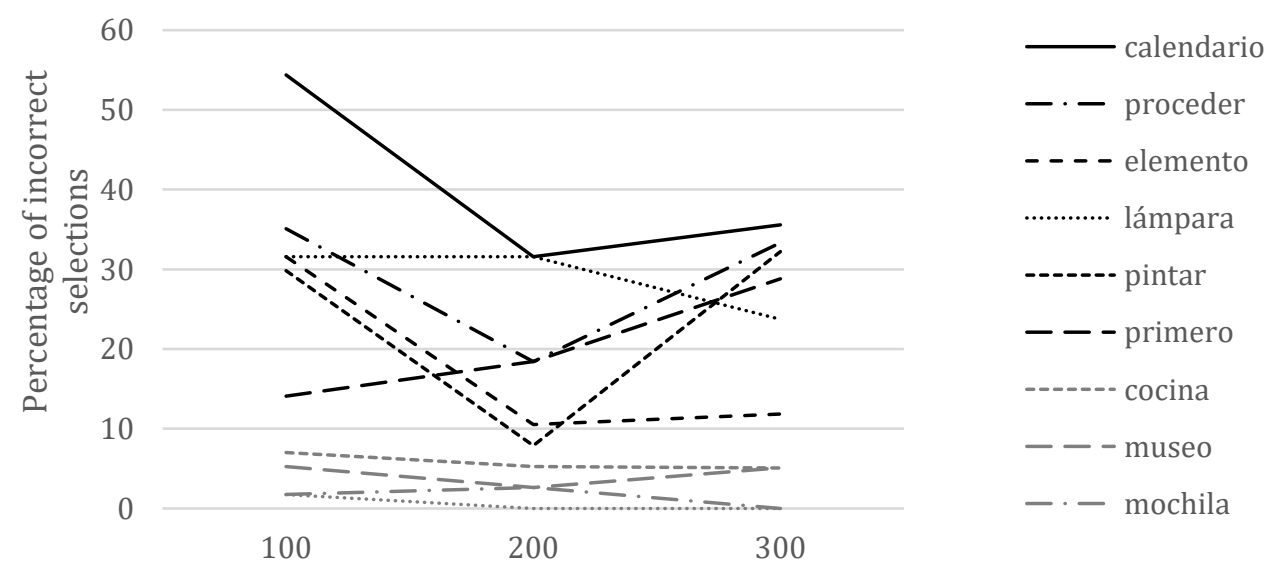

Figure 3. Percentage of incorrect selection of simple words by level 
In order to further explore the pattern of incorrect identifications of simple words, Figure 3 presents the developmental trajectories for each of the filler words in the test. As can be observed, four of them (cocina, museo, mochila, mañana) were rarely identified as complex, whereas the other six presented different patterns across levels. The two verbs (proceder, pintar) presented high levels of incorrect identifications at the 100 and 300 level but less so at the 200 level. One possible explanation is that 100 level courses are extremely focused on the teaching of verbal inflectional morphology, which puts a strong emphasis in verb endings and students get used to seeing verb roots stripped of their inflectional ending. As they discover that verb endings are not necessarily derivational but mostly convey information about tense, aspect or person, they may refrain from considering all verbs as complex. Finally, as they notice that some verbs are indeed derived from adjectives (ameno [fun] -> amenizar [make something fun] or nouns (negocio [business] -> negociar [negotiate]), they might overgeneralize that knowledge and consider most verbs as results of a derivative process.

Calendario and elemento present a parallel evolution, even though the former starts with higher levels of wrong identification than the latter. In both cases, they include a word ending that is indeed a suffix in lots of complex words: -ario and -mento, which could easily trigger the identification of the word as composed of more than one morpheme. In the case of calendario, from a diachronic perspective, that interpretation would not be incorrect, given that the word calendarium (from calenda and -arium) already existed in Latin. However, from a synchronic viewpoint, it is not composed of a Spanish root and a Spanish suffix, through a productive derivational process, as is the case of primero, which comes from the already a fully formed Latin word: primarius. In such contexts, incorrect identifications seem to be driven by the visual recognition of a suffix, without paying attention to the fact that no Spanish word remains once the suffix is stripped. In the case of calendario and elemento, learners seem to start performing this second check in search for a viable root by level 200, which explains the decrease in incorrect identifications at that level and further. When it comes to primero, the situation is further complicated by the fact that the word prime does exist in English, with a meaning that is similar to that expressed in primero. This may explain the increasing levels of incorrect identifications per level. A similar situation may explain why lámpara also presents high error rates. Indeed, while the suffix -ara is not a productive one in Spanish, the fact that lamp is a word in English may incorrectly drive the learners to believe that lámpara is composed of lamp and -ara.

\subsubsection{Study 2: Instructional study}

As can be observed in Figure 4, the number of correct segmentations is highest in the pretest for the critical group. Further analyses to confirm this visual inspection of the data are provided in the next sections for the average number of both correct detections and correct segmentations. 


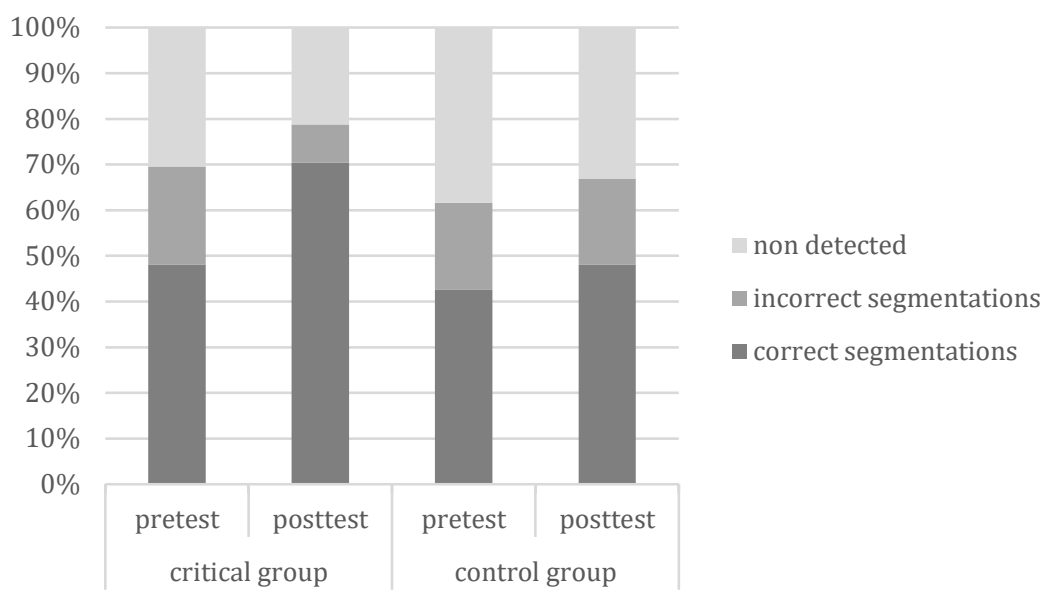

Figure 4. Percentage of correct segmentations, incorrect segmentations and undetected complex words in the pretest and posttest for the control and critical group

A repeated factor anova was carried out on the mean number of correct detections per participant. The anova had two factors of two levels each: (1) group (critical vs. control) and testing time (pre-test vs. post-test). No simple effect of group or testing time reached significance, nor did the interaction between both. This indicates that, as was the case in the cross-sectional study, the number of correct detections reaches a ceiling very quickly and an intensive morphological training does not seem to be sufficient for improvements to be observable after that ceiling is attained.

Table 4. Average number of correct detections and segmentations, with standard

deviations, in the pre-test and post-test for both the critical and control group

\begin{tabular}{|c|l|l|l|l|}
\hline \multirow{2}{*}{} & \multicolumn{2}{|c|}{ Correct detections } & \multicolumn{2}{c|}{ Correct segmentations } \\
\cline { 2 - 5 } & $\begin{array}{c}\text { Control } \\
\text { group }\end{array}$ & $\begin{array}{c}\text { Critical } \\
\text { group }\end{array}$ & $\begin{array}{c}\text { Control } \\
\text { group }\end{array}$ & $\begin{array}{c}\text { Critical } \\
\text { group }\end{array}$ \\
\hline Pre-test & $6.16(2.02)$ & $6.96(1.78)$ & $4.26(1.77)$ & $4.81(1.74)$ \\
\hline Post-test & $6.69(1.99)$ & $7.88(1.56)$ & $4.81(2.37)$ & $7.04(1.64)$ \\
\hline
\end{tabular}

A second repeated measures anova was carried out on the mean number of correct segmentations per participant, which presented a significant interaction between testing time and group, $\mathrm{F}(1,50)=5,425, \mathrm{p}<.05$. Results show that progress between the pre-test and the post-test was only significant in the critical group. As can be observed in Table 4, while the control group correctly segmented 4.81 words out of the 6.69 that were detected, on average, the critical group correctly segmented 7.04 of the 7.88 words they had correctly recognized as morphologically complex. This means that, even though the critical group did not improve in terms of the number of words they identified as containing more than one morpheme, their ability to determine what specific morphemes were included in those words did increase after the morphological treatment. This indicates that, in this receptive activity, the morphological training had a more relevant effect on the distributional aspect of the task than on the relational one. 


\subsection{Productive task}

\subsubsection{Study 1: Cross-sectional study}

The data were first divided into three categories: real words, possible words, and impossible words. Figure 5 shows that, at all course levels, the majority of the items that students wrote in response to the suffixes were impossible creations. In the following sections, the average number of real and possible words will be studied further in order to analyze whether learners did improve in those two areas even though most of their contributions were erroneous.

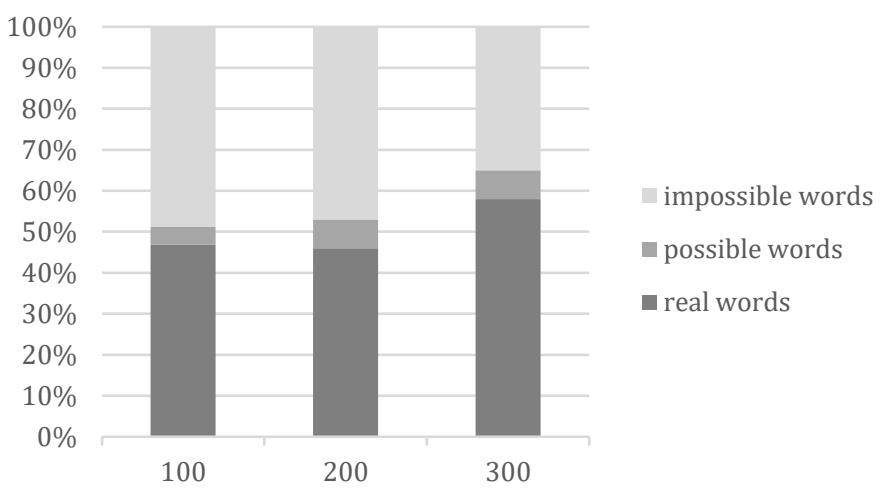

Figure 5. Percentage of real, possible and impossible words per course level

A one-way anova was carried out on the mean number of real words that participants wrote on average per suffix, with a three-level factor of course level (i.e., $100,200,300)$. Results show a significant main effect of course level, $F(2,162)=18,594$, $\mathrm{p}<.001$, which indicates that learners were remembering an increasingly higher number of words when given a suffix as a trigger. A series of post-hoc pairwise comparisons with a Bonferroni correction were carried out and revealed that significant differences were observable between levels 100 and 300, as well as 200 and 300. This indicates that no significant increases could be seen after only one year of Spanish language courses and that the passage from second year of SSL courses to the major was where the real improvement could be detected.

Table 5. Average number of correct words per participant, with standard deviation, per course level

\begin{tabular}{|c|c|}
\hline \multicolumn{1}{|c|}{ Course } & \multicolumn{2}{|c|}{ Average number of } \\
level & $\begin{array}{r}\text { porrect words per } \\
\text { participant }\end{array}$ \\
\hline 100 & $2.87(1.89)$ \\
\hline 200 & $3.8(1.94)$ \\
\hline 300 & $5.56(3.23)$ \\
\hline
\end{tabular}

A second one-way anova was carried out on the mean number of possible words that participants wrote on average per suffix, with a three-level factor of course level (i.e., 100, 200, 300). No effect of course level was observed, and the average did not even 
reach one word per person (i.e., $100=0.31,200=0.41$, and $300=0.6$ ) in any of the levels. This indicates that forming new words based on a suffix was an exceedingly difficult task for students at all levels.

\subsubsection{Study 2: Instructional study}

As evidenced in Figure 6, while the control group shows similar patterns to those observed in the cross-sectional study, students in the critical group did write more real and possible words than impossible ones. Strangely, this is also the case in the pretest, which indicates that the learners in this group were overall better at this particular task from the beginning. Given that participants were randomly assigned to the control and critical groups, there is no obvious reason to explain this pattern in the pretest. In the next sections, the evolution from pretest to posttest in both groups will be compared across groups for both the real and the possible words.

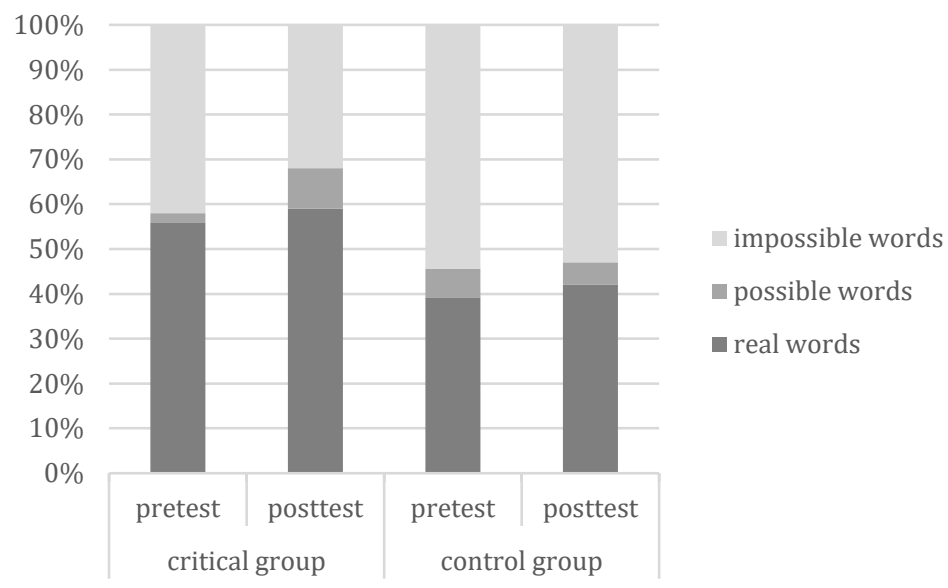

Figure 6. Percentage of real, possible and impossible words in the pretest and the posttest for the critical and control group

A repeated factor anova was carried out on the mean number of real words written per suffix by participant. The anova had two factors of two levels each: (1) group (critical vs. control) and (2) testing time (pre-test vs. post-test). A significant main effect of group was found, indicating that the critical group had better overall results than the control group. This difference was particularly daunting in the pre-test results, as evidenced on Table 6. Results also show a significant interaction of testing time and group, $F(1,60)=22,616, p<.01$, with a clear advantage of the critical group over the control group in terms of how much improvement was observed from the pre- to the post-test. 
Table 6. Average number of correct and possible words per participant, with standard deviation, in the pre-test and post-test for both the control and critical group

\begin{tabular}{|c|c|c|c|c|}
\hline \multirow{2}{*}{} & \multicolumn{2}{|c|}{ Correct words } & \multicolumn{2}{c|}{ Possible words } \\
\cline { 2 - 5 } & $\begin{array}{c}\text { Control } \\
\text { group }\end{array}$ & $\begin{array}{c}\text { Critical } \\
\text { group }\end{array}$ & $\begin{array}{c}\text { Control } \\
\text { group }\end{array}$ & $\begin{array}{c}\text { gritical } \\
\text { group }\end{array}$ \\
\hline Pre-test & $2.94(2.09)$ & $5.21(2.11)$ & $0.48(0.71)$ & $0.1(0.41)$ \\
\hline Post-test & $3(2.38)$ & $8.39(2.85)$ & $0.39(0.75)$ & $0.97(0.94)$ \\
\hline
\end{tabular}

Another repeated factor anova was carried out on the mean number of possible words written per suffix by participant. A significant interaction between group and testing time was found, $F(1,60)=15,525, \mathrm{p}<.01$. Indeed, the critical group presented a more significant increase from pre- to post-test than the control group. Concretely, after the morphological training, learners were able to form one possible word, on average, whereas not even one student out of two was able to do so in the control group. While these data do not seem very impressive, they do indicate that, on average, students in the critical group were all able to create at least one word by correctly applying the word formation rules that are specific to a given suffix. Therefore, while the morphological treatment did not seem to significantly impact the development of the purely relational part of this productive task, it did seem to have a detectable (although not huge) effect on the distributional aspect of the task.

\section{Discussion}

This study aimed to assess the impact of an intensive short-term derivational morphology training on the development of two distinct aspects of morphological awareness: relational and distributional knowledge, both at the receptive and the productive level. Results overall confirm that including some morphological contents in the SSL curriculum would be an easy way to quickly improve learners' morphological skills. Indeed, while none of the tasks improved from level 100 to 200 in the crosssectional study, three of them showed better results in the post-test after four sessions of the pedagogical treatment even though participants were enrolled in level 100 courses. This does not mean that none of the tasks evolved over time, as two of them did so, from level 200 to 300 , indicating that in those two tasks, the effect of the treatment was mostly to accelerate a learning process that would normally take at least another year. In the distributional sub-task of the productive task, however, no evolution at all was observed, even at the 300 level, but the morphological training did result in clear progress.

Table 7. Summary of the improvements observed across levels, in the cross-sectional study, and between the pre-test and the post-test, in the instructional study

\begin{tabular}{|c|c|c|c|c|}
\hline & \multicolumn{2}{|c|}{ Receptive task } & \multicolumn{2}{c|}{ Productive task } \\
\hline & Relational & Distributional & Relational & Distributional \\
\hline $100-200$ & No & No & No & No \\
\hline $200-300$ & No & Yes & Yes & No \\
\hline Pre - post & No & Yes & Yes & Yes \\
\hline
\end{tabular}


Looking at the results task by task, the receptive-relational task is the only one that does not present any significant evolution, either at the end of the Spanish major, or after the morphological treatment. What is interesting about this task is that students show over $60 \%$ of accuracy from level 100 , which is a reasonably good result for learners who have taken only one semester of Spanish, and do not improve after that, even in the case of students who are the end of a major in Spanish. Future research could look into factors that may be playing a role in these results. For instance, it would be relevant to study whether a longer morphological treatment, or one that is specifically focused on the recognition of problematic suffixes, may be more effective than the one proposed here, which was relatively short and included a great variety of different suffixes.

The receptive - distributional task presents a different pattern of results, as it improves from level 200 to 300 and is also positively affected by the training. However, students at the 300 level are able to correctly segment 6.12 of the detected complex words, on average, whereas learners in the critical group could segment 7.04 words. When taking into account the amount of words that were detected in each group in the first place, students in 300 courses could segment $83.38 \%$ of the words they recognized as complex, whereas, this percentage raises to $89.34 \%$ for the learners in 100 courses who participated in the morphological treatment. Thus, while the skills required to complete the task did improve over time, as students developed their overall linguistic proficiency in Spanish, a short pedagogical intervention was sufficient to surpass the results obtained after three of language courses at the university level.

Similar to the results in the previous task, the productive - relational task also improved both from 200 to 300 course levels, and after the morphological training. Nonetheless, the number of correct words written by the students who participated in the critical group is clearly higher (8.39) than that of students at the 300 level (5.56). While this advantage of the training seems obvious, one needs to remember that the critical group started with a very high result for this particular task (5.21). Therefore, a better comparison between 300-level students and those in the critical group can be made by comparing the difference in results from 100 to 300 courses, on the one hand, and pre- to post-test on the other. The former comparison indicates an increase of 2.69 in the former, as opposed to 3.18 in the latter. This shows that the training achieves a similar increase of approximately 3 more words to that achieved after three years of language courses with no explicit morphological training.

Additionally, the results from the cross-sectional data could have been interpreted as a byproduct of the larger lexicon of students enrolled in higher course levels. Indeed, this fluency task does require to know a certain amount of words in order to be able to associate them with one another in terms of their morphological relation. In this context, it seems only natural that students with higher levels of proficiency remember more words than learners at lower proficiency levels. However, increased vocabulary breadth alone could not explain why learners in 100 level courses present better results than students in 300 level courses after only four weeks of a morphological treatment which did not focus on vocabulary teaching. 
The last task, which tested learners' ability to create possible words based on given suffixes, did not evolve at all in the cross-sectional study, and students only showed improved results after participating in the morphological training. But, even then, students were only able to create one possible word, on average, that accurately followed word formation rules. Furthermore, 32\% of the items written by the students in the critical group were impossible words that violated distributional restrictions of Spanish suffixes. This number, however, rises to $53 \%$ in the case of the control group. In sum, while it seems that a short-term morphological training does not allow learners to create a great variety of invented words, they make fewer incorrect attempts and most students are able to create at least one new word per suffix. Alternatively, only $40 \%$ to $50 \%$ of the learners in all other groups accurately created one new word.

Overall, the data in this study point to the clear benefits of a short morphological training in the development of distributional and relational knowledge, both at the receptive and productive level. While this was true in all but one task, which had reached a ceiling, it was particularly evident in the case of the productive distributional task, where students did not show any sign of improvement after three years of language courses, but greatly evolved after four sessions of morphological treatment. This last result is not surprising in light of Marcos Miguel's (2012) and Whitley's (2004) studies, where they hypothesized that the aspect of morphological knowledge that was most challenging for Spanish learners was the distributional one. The present study shows that such challenges can be addressed by exposing students to a short and intensive training, which does not require to change the overall curriculum of the course and can take as little as four sessions of 25 minutes.

Understandably, given the limited treatment given to derivational morphological skills in textbooks, even developing a short training like the one proposed here may seem like a daunting task for instructors who are not as familiar with word formation processes. Therefore, we suggest that useful information can be found about (1) specific suffixes that may require more attention than other in the classroom, and (2) a description of the forms and uses of most Spanish suffixes. The first point can be addressed by reading Sánchez Gutiérrez, Marcos Miguel and Robles García (2020), where the authors establish a list of suffixes that are known to be more difficult to use for L1 speakers of English who learn SSL based on a corpus analysis. The second point is directly addressed in Serrano Dolader (2018), where one can find a detailed description of most suffixes in Spanish, their use, meaning, distributional restrictions, etc. as well as proposed activities to practice them.

\section{Conclusion}

This study aimed to shed some light on the specific aspects of derivational morphology that benefit the most from an explicit morphological treatment in the classroom. Results from a cross-sectional study and from an instructional study show that explicit teaching is advantageous for most tasks, but particularly so for those that tend to not improve over time as students develop their overall linguistic proficiency in SSL. These data demonstrate that more attention should be given to this particular aspect of morphological awareness, by providing the students with information about 
word formation rules in Spanish and allowing them to practice word creation skills based on their acquired knowledge of specific suffixes.

\section{References}

BOWERS, P. and KIRBY, J. (2010). «Effects of morphological instruction on vocabulary acquisition». Reading and Writing, 23, 515-537.

CARLISLE, J. (1995). «Morphological awareness and early reading achievement». In L. B. Feldman, Morphological aspects of language processing (pp. 189-209). Hillsdale, NJ: Erlbaum.

COUNCIL OF EUROPE (2001). Common European Framework of Reference for Languages: learning, teaching, assessment. Cambridge: Cambridge University Press.

DE MIGUEL GARCÍA, M. L. (2005). La enseñanza del léxico del español como lengua extranjera. Resultados de una encuesta sobre la metodología aplicada en el aula. MarcoELE. Revista de Didáctica Español Lengua Extranjera, (1), 1-21.

FRIEDLINE, B. E. (2011). Challenges in the second language acquisition of derivational morphology: From theory to practice (Unpublished doctoral dissertation). University of Pittsburgh, PA.

HU, H. C. M., and NASSAJI, H. (2014). «Lexical inferencing strategies: The case of successful versus less successful inferencers». System, 45, 27-38.

INSTITUTO CERVANTES. (2006). Plan curricular del instituto cervantes. Niveles de referencia para el español. Madrid: Instituto Cervantes-Biblioteca Nueva.

MARCOS MIGUEL, N. (2012). «Grapho-morphological awareness in Spanish L2 reading: how do learners use this metalinguistic skill?». Language Awareness, 21(1-2), 197213.

MARCOS MIGUEL, N. (2017). «Instruction in derivational morphology in the Spanish L2 Classroom: What do teachers believe and do?». Konińskie Studia Językowe, 5(1), 37 60.

MARCOS MIGUEL, N. (2018). «Analyzing morphology-related strategies in Spanish L2 lexical inferencing: how do suffixes matter?». International Review of Applied Linguistics in Language Teaching, 1(ahead-of-print).

MARCOS MIGUEL, N., \& SÁNCHEZ GUTIÉRREZ, C. H. (2020). ¿Solamente o solamento?: desafíos en el aprendizaje de forma y significado de-mente y-miento/-mento por hablantes de ele.

MORIN, R. (2006). «Building Depth of Spanish L2 Vocabulary by Building and Using Word Families». Hispania, 89(1), 170-182.

MORIN, R. (2003). «Derivational morphological analysis as a strategy for vocabulary acquisition in Spanish». The Modern Language Journal, 87(2), 200-221.

NASSAJI, H. (2003). «L2 vocabulary learning from context: Strategies, knowledge sources, and their relationship with success in L2 lexical inferencing».Tesol Quarterly, 37(4), 645-670.

NASSAJI, H. (2006). «The relationship between depth of vocabulary knowledge and L2 learners' lexical inferencing strategy use and success». The Modern Language Journal, 90(3), 387-401. 
NATION, I. S. P. (2001). Learning vocabulary in another language. Cambridge, UK: Cambridge University Press.

ROBLES GARCÍA, P. \& SÁNCHEZ GUTIÉRREZ, C. (2017). «La morfología derivativa en los manuales de español estadounidenses: Un estudio exploratorio». Revista de la asociación española de lingüística aplicada, 15(1), 70-86.

SÁNCHEZ GUTIÉRREZ, C. (2014). «Morfología derivativa y manuales de E/LE: un análisis crítico». Anexos de la Revista Española de Lexicografía, 31, 163-178.

SÁNCHEZ-GUTIÉRREZ, C. and HERNÁNDEZ-MUÑOZ, N. (2018). «Development of derivational morphological awareness in anglophone learners of Spanish: A relational knowledge study». Foreign Language Annals, 51, 369-388.

SÁNCHEZ-GUTIÉRREZ, C. H., MARCOS MIGUEL, N., \& GARCÍA, P. R. (2020). «What derivational suffixes should we teach in Spanish as a Second Language courses?». Hispanic Linguistics: Current issues and new directions, 26, 75.

SERRANO DOLADER, D. (2018). Formación de palabras y enseñanza del español LE/L2. Abingdon: Routledge.

SCHMITT, N. (2014). «Size and depth of vocabulary knowledge: What the research shows». Language learning, 64(4), 913-951.

THURSTONE, L. L. (1938). Primary mental abilities. Chicago: University of Chicago Press.

TYLER, A., \& NAGY, W. (1989). The acquisition of English derivational morphology. Journal of memory and language, 28(6), 649-667.

WHITLEY, S. (2004). Lexical errors and the acquisition of derivational morphology in Spanish. Hispania, 87(1), 163-172. 